\title{
Catalyst and Catalysis for Fischer-Tropsch Synthesis: A Comparative Analysis of Iron and Cobalt Catalysts on SBA-15 \\ Mala A Sainna ${ }^{1 *}$ and Abba MK $^{2}$
}

${ }^{1}$ Manchester Institute of Biotechnology and School of Chemical Engineering and Analytical Science, The University of Manchester, 131 Princess Street, Manchester M1 $7 D N$, United Kingdom

${ }^{2}$ Department of Petroleum Engineering, Faculty of Engineering and Engineering Technology, Abubakar Tafawa Balewa University Bauchi, PMB 0248, Yelwa Road, Bauchi State, Nigeria

\begin{abstract}
The influence of Cobalt and iron loading, cobalt and iron precursor, and the effect of promoters(Mg and $\mathrm{Mn})$ on the physico-chemical properties as well as the catalytic properties and structural appearance of mesopourous Co/ SBA-15, Fe/SBA-15 and bimetallic Fe, Co/SBA-15 catalysts for Fischer-Tropsch (FTS) reaction is investigated. The various prepared catalysts were characterized by X-ray diffraction (XRD), scanning electron micropscope (SEM), Energy dispersion X-ray diffraction (EDX) and Temperature programmed reduction (TPR). For the Co/SBA-15 and Fe/SBA-15 prepared and promoted with Magnesium and manganese (Mg, Mn), the dispersion of the metal loaded (Fe, $\mathrm{Co}$ ) increases significantly when compared to the un-promoted Co/SBA-15 and Fe/SBA-15, and the dispersion of metal loaded ( $\mathrm{Co}, \mathrm{Fe}$ ) was found to be higher with $\mathrm{Mg}$ than $\mathrm{Mn}$ promoter. The bimetallic catalyst was also found to have a higher dispersion of the metals than a single metal loaded catalyst (Co/SBA-15, Fe/SBA-15). Promoting the catalyst with $\mathrm{Mn}$ increases dispersion but it was said to decrease reducibility leading to a catalyst that is less reactive than the un-promoted one [1-3]. The mesopourous catalyst prepared did not show any crystal growth in their meso-channels which propose the dispersion of the active metals on the mesopore and the formation of tiny crystals (nanocrystal) undetectable by the $\mathrm{X}$-ray diffractogram. The absence of an intense peak of the crystals $\left(\mathrm{Co}_{3} \mathrm{O}_{4}, \mathrm{Fe}_{3} \mathrm{O}_{4}\right)$ at an expected angle might be due to the existence of ions of cobalt and iron which might be existing as a nanocluster or due to the disintegration of the mesopores structures.
\end{abstract}

Keywords: Fischer-Trosch; Catalyst; Heterogeneous catalyst; Preparation; Characterization

\section{Introduction}

The search for alternatives to non-renewable energy, such as crude oil and to provide a sulphur free fuel is becoming an interesting field of study to scientist and researchers all over the world. Hydrogenation of carbon monoxide (CO) with several catalysts such as, nickel, cobalt, and iron to produce mostly alkanes, alkenes and oxygen containing compounds as by-products is known as Fischer- Tropsch Synthesis (FTS). The mechanism for the reaction is predicted to follow a stepwise chain growth of hydrocarbons, according to Schulz-Flory Distribution [4-13]. Currently, the main commercial interest in Fischer-Tropsch (F-T) process is the production of high quality sulphur-free synthetic diesel fuels from natural gas. The formation of hydrogen and carbon monoxide $\left(\mathrm{CO}+\mathrm{H}_{2}\right)$ commonly referred to as synthesis gas, involves several processes such as dry reforming of methane, partial oxidation of methane, steam reforming and water gas shift reaction. This process serves as routes to producing fuel precursors and chemicals used in refineries and petrochemical plants making the F-T process viable [913]. The renewed interest in F-T synthesis, is probably not because of the abundant natural gas in the globe, but because of the global demand for fuel supplies and environmental policies placed on the quality of fuel emitted to the environment. While the concept of hydrogen fuel and biomass remains an important option for fossils fuel, synthetic fuel produced by the F-T process is currently promoted as the fuel for the future. However, the maximum potential of the F-T process is yet to be achieved. This is because, the cost of running an F-T plant is expensive compared to the direct production of gasoline and diesel via crude oil. Consequently, research and huge investments in Europe, Asia, Africa and the U.S to improve the amount of $\mathrm{C}_{2}-\mathrm{C}_{4}$ olefins is proliferated. The research is aimed at optimizing the selectivity of cracking high-boiling waxy hydrocarbons that can be converted through cracking processes to any desired hydrocarbon of any length [14-18]. The F-T reaction is highly exothermic and very slow. Catalyst is therefore required to increase the rate of reaction and reduce the energy consumed during the reaction. Gleaves et al. [19] used and modified several heterogeneous catalysts by promoting the catalyst with mostly metals from Group VIII. For example, coke deposition on $\mathrm{Ru}, \mathrm{Fe}, \mathrm{Co}, \mathrm{Rh}, \mathrm{Pd}, \mathrm{Pt}$, and Ir affects the mechanism [17-19]. Roa et al. [20] illustrated that the deposition of coke on metal surfaces are as a result of disproportionation of $\mathrm{CO}$ and cracking of hydrocarbons during the reaction. This can de-activate the catalyst and reduce product yield. Meanwhile, Basini et al. [21], tried to understand the mechanism of F-T reaction on different catalyst optimizing steam/carbon and oxygen/carbon as feed stock. They suggested that, majority of group VIII metals are catalytically active for the reaction, but their resistance to coke deposition on catalyst performance decreases across the periodic table. Whereas, noble metals, such as $\mathrm{Pt}$, and $\mathrm{Rh}$, have been reported to be more resistant to coke deposition and used as promoters [22], however, they are very expensive and not used on large scale, as compared to nickel, cobalt and iron which are widely used in large scale (Scheme 1).

In this report, we thoroughly investigated and rationalized the influence of Cobalt and iron loading, cobalt and iron precursor, and the effect of $\mathrm{Mg}$ and $\mathrm{Mn}$ promoters on the physico-chemical properties as well as the catalytic properties and structural appearance of mesoporous

*Corresponding author: Mala A Sainna, Manchester Institute of Biotechnology and School of Chemical Engineering and Analytical Science, The University of Manchester, 131 Princess Street, Manchester M1 7DN, United Kingdom, E-mail: alhaji.mala@manchester.ac.uk

Received June 08, 2016; Accepted June 16, 2016; Published June 25, 2016

Citation: Sainna MA, Abba MK (2016) Catalyst and Catalysis for Fischer-Tropsch Synthesis: A Comparative Analysis of Iron and Cobalt Catalysts on SBA-15. J Thermodyn Catal 7: 172. doi:10.4172/2160-7544.1000172

Copyright: (c) 2016 Sainna MA, et al. This is an open-access article distributed under the terms of the Creative Commons Attribution License, which permits unrestricted use, distribution, and reproduction in any medium, provided the original author and source are credited. 


$$
\begin{array}{llll}
\mathrm{CH}_{4}+1 / 2 \mathrm{O}_{2} & \rightarrow & \mathrm{CO}+2 \mathrm{H}_{2} & \Delta \mathrm{H}=38 \mathrm{~kJ} / \mathrm{mole} \\
\mathrm{CH}_{4}+\mathrm{CO}_{2} \rightarrow 2 \mathrm{CO}+2 \mathrm{H}_{2} & \Delta \mathrm{H}=-247 \mathrm{~kJ} / \mathrm{mol} \\
\mathrm{CO}+\mathrm{H}_{2} \mathrm{O} \rightarrow \mathrm{CO}_{2}+\mathrm{H}_{2} & \Delta \mathrm{H}=41 \mathrm{~kJ} / \mathrm{mol} \\
\mathrm{CH}_{4}+\mathrm{H}_{2} \mathrm{O} \rightarrow 2 \mathrm{CO}+3 \mathrm{H}_{2} & \Delta \mathrm{H}=-206 \mathrm{~kJ} / \mathrm{mol}
\end{array}
$$

Scheme 1: The synthesis gas production is performed by different processes, this processes includes partial oxidation of methane (1), Dry reforming of methane (2), Water gas shift reaction (3) and Steam methane reforming (4) [8].

Co/SBA-15, Fe/SBA-15 and bimetallic Fe, Co/SBA-15 catalysts for Fischer-Tropsch synthesis (FTS). The various catalyst prepared within this report is characterized using XRD, SEM, EDX, and TPR which is thoroughly discussed in the result section of the report.

\section{Experimental Methods}

\section{Sol-Gel method}

The mesoporous silica support $\left(\mathrm{SiO}_{4}\right)$ was prepared using procedure of Sol-Gel method as reported in previous work [22]. Reagents and solvents were purchased from commercial sources and purified by standard procedures before use.

\section{SBA-15}

The preparation of SBA-15 support is synthesised as follows: 8 grams of tri-block copolymer $\mathrm{P} 123$ (EO $\mathrm{PO}_{7} \mathrm{EO}_{20}$ also known as the poly (ethylene glycol)-poly (propylene glycol)-poly (ethylene-glycol)) is measured using an electronic weighing balance and dissolved in 240 grams of de- ionized (DI) water in a polyethylene bottle. The solution in the polyethylene bottle was placed in a glass bowl containing water and kept on a hot plate at $40^{\circ} \mathrm{C}$ for 6 hours under stirring at 545 $\mathrm{rpm}$, until the whole solute P123 is completely dissolved, leading to a clear solution. $40 \mathrm{ml}$ of $37 \% \mathrm{HCl}$ is then slowly added using $50 \mathrm{ml}$ measuring cylinder by dropping on the solution to reduce the $\mathrm{pH}$ of the solution. 10 munities later, $18.5 \mathrm{ml}$ Tetraethylorthosilicate (TEOS) is slowly dropped in (approximately 30 drop per minute) the mixture was kept for $24 \mathrm{hrs}$ at $40^{\circ} \mathrm{C}$ under stirring condition for Hydrolysis and condensation reactions to complete. A white precipitated solution was formed which was then transferred into an oven at $95^{\circ} \mathrm{C}$ for 24 hours to age without stirring. The white solute precipitate was then filtered, washed sufficiently with approximately $600 \mathrm{ml}$ of DI water to remove the template (P123) and afterwards the white solute powder was dried in an oven at $60^{\circ} \mathrm{C}$ for 24 hours using a glass watch vessel. The white powdered solute was removed from the oven and transferred into a crucible for calcinations under static condition for 6 hours at $550^{\circ} \mathrm{C}$ by setting the crucible to increase temperature to $5^{\circ} \mathrm{C}$ per minute and after heating for 6 hours it was cooled at $10^{\circ} \mathrm{C}$ per minute and finally the pure mesoporous silica was called the SBA-15 [21-25].

\section{Metal loading by wet impregnation}

Preparation of cobalt active catalyst by wet impregnation method: In wet impregnation, the cobalt loading on the channels of the mesoporous silica support is defined as the weight percentage of elemental Co in the catalysts. The equations below signifies the steps to follow in obtaining the percentage of the cobalt precursor used for the cobalt loading and the amount of the cobalt loaded in the channels of the SBA-15 silica support used; i.e.,

$$
\text { weight of cobalt }=\frac{\text { Molar weight of Cobalt } \times \text { weight of Cobalt nitrate }}{\text { Relative molecular weight of Cobalt nitrate }}
$$

To identify the weight of cobalt in a given weight of support, the weight of cobalt obtained using the equation above divided by the summation of the weight of a given support and the weight of cobalt obtained using eqn. (1) above, multiplied by 100 to obtain the percentage of the cobalt loaded in the channels of the given support. It is simplified as shown below;

$$
\text { weight of Cobalt in given weight of support } \%=\frac{\text { Weight of cobalt } \times 100}{\text { Weight of support }+ \text { weight of cobalt }}
$$

The concentration of the precursor used in the DI water in which it is dissolved is denoted as the equation below;

$$
\mathrm{M}_{1} \mathrm{~V}_{1}=\mathrm{M}_{2} \mathrm{~V}_{2}
$$

Where;

$$
\begin{aligned}
& M_{1}=\text { Molarity of water } \\
& V_{1}=\text { Volume of water } \\
& M_{2}=\text { Molarity of salt precursor } \\
& V_{2}=\text { Volume of salt precursor }
\end{aligned}
$$

The equation below is used to measure the concentration of the salt precursor used and the DI water or absolute alcohol;

$$
\text { Concentration }\left(\frac{\mathrm{Mol}}{\mathrm{dm} 3}\right)=\frac{\text { Mass }}{\text { Molarmass }}
$$

The preparation of Co/SBA-15 by wet impregnation is conducted by the addition of $10 \mathrm{ml}$ of absolute alcohol (ethanol) with 2 grams of $\mathrm{Co}\left(\mathrm{NO}_{3}\right)_{2} .6 \mathrm{H}_{2} \mathrm{O}$ in a round bottom flask with a short condenser at the top of the flask to condense the evaporated alcohol in the solution and the flask is kept in a bowl containing water, the mixture is stirred for at least 60 munities under $50^{\circ} \mathrm{C}$ on a hot plate to dissolve the salt precursor thoroughly (however the amount of the salt precursor was added according to the percentage of the metal required within the channels of the SBA-15 silica support), then 0.5 grams of the calcined mesoporous SBA-15 silica is added gently on the salt solution and allowed to stir for another 120 minutes at $50^{\circ} \mathrm{C}$. The solution is left to cool till it is at room temperature then $10 \mathrm{ml}$ of DI water is added to reduce the viscosity of the solution. The solution is then filtered and without washing the filtrate it is then dried in a vacuum oven for 60 minutes at a temperature of $120^{\circ} \mathrm{C}$ and a pressure of $800 \mathrm{psi}$. After drying, the sample is calcined at a temperature of $400^{\circ} \mathrm{C}$ for 4 hours by setting the crucible to a heating rate of $10^{\circ} \mathrm{C}$ per minutes and later cooled at $10^{\circ} \mathrm{C}$ per munities, to obtain the mechanical required structure of the catalyst. And finally the sample obtained is known as the Co/SBA- 15 active catalyst.

Preparation of cobalt active catalyst with promoter using wet impregnation method: The preparation of active catalyst with promoter using wet impregnation method is conducted by the addition of $10 \mathrm{ml}$ of absolute alcohol with 2 grams of the salt precursor together with 1 gram of Magnesium nitrate. Add both precursors in a round bottom flask containing $10 \mathrm{ml}$ of absolute alcohol, stir for 1 hour at $50^{\circ} \mathrm{C}$ on a hot plate then add 0.5 grams of the calcined SBA- 15 silica and allow to stir for another 2 hours, allow the solution to cool to room temperature then filter. Dry the filtrate in a vacuum heat for 1 hour at $12^{\circ} \mathrm{C}$ and calcine for 4 hours at $400^{\circ} \mathrm{C}$ with a heating rate of $10^{\circ} \mathrm{C}$ per minute followed by a cooling rate of $10^{\circ} \mathrm{C}$ per minute. The active catalyst obtained is expected to have a better dispersion as well as activity and selectivity due to the promoter within the channels of the mesoporous SBA-15 catalyst support. The amount of the metal deposited on the channels is measured by using X-ray diffractions (XRD) [26-51].

Preparation of bimetallic active catalyst by co-impregnation method: The bimetallic active catalyst $\left(\mathrm{Co}-\mathrm{Fe} / \mathrm{SiO}_{2}\right)$ is prepared by the addition of 1.3 grams of cobalt nitrate hexahydrate, which is equivalent 
Citation: Sainna MA, Abba MK (2016) Catalyst and Catalysis for Fischer-Tropsch Synthesis: A Comparative Analysis of Iron and Cobalt Catalysts on SBA-15. J Thermodyn Catal 7: 172. doi:10.4172/2160-7544.1000172

to $35 \%$ theoretically, and 1.2 grams of iron (III) nitrate which is also equals to $36 \%$ and the two precursors are stirred to dissolved in absolute alcohol under $50^{\circ} \mathrm{C}$ for 1 hour followed by the addition of 0.5 grams of the calcined SBA-15 silica slowly in the homogeneous solution. The solution is allowed to stir at $50^{\circ} \mathrm{C}$ for 2 more hours which is then filtered and dried under $120^{\circ} \mathrm{C}$ for 1 hour in a vacuum oven. The dried sample is calcined for 4 hours at $400^{\circ} \mathrm{C}$ by the same heating and cooling rate as explained in the above procedure, and an orange powder is obtained.

\section{Results and Discussion}

\section{Energy dispersive $\mathrm{X}$-ray spectroscopy results}

The energy dispersive $\mathrm{x}$-ray spectroscopy (EDX) is an investigative method used in the chemical characterization or elemental analysis of the sample prepared. We utilized it to display the various samples of the catalyst prepared which were supported on silica SBA-15 were shown by elemental composition to note the amount of metal loaded (Fe, Co, $\mathrm{Mg}$ and $\mathrm{Mn}$ ) after preparation of the samples using wet impregnation method. All the samples were prepared using DI water as a solvent instead of ethanol to dissolve the metal precursor and the concentration ranging from $0.46 \mathrm{M}$ to $0.49 \mathrm{M}$. The samples characterized by means of EDX were recognized as $\mathrm{x}$-SBA/15-n; where $\mathrm{x}$ refers to the percentage of the metal loaded in a sample, and the $\mathrm{n}$ is the various numbers of the samples prepared (Figures 1-7 and Tables 1-7).

\section{Scanning Electron Microscope (SEM) images evaluation}

The scanning electron microscope is basically used to determine the samples composition, surface topology and some other properties like the electrical conductivity when electrons from the SEM interact with the atoms that unite to form the sample [52]. The Figures 8 and 9 below indicate the cobalt supported catalyst and iron supported

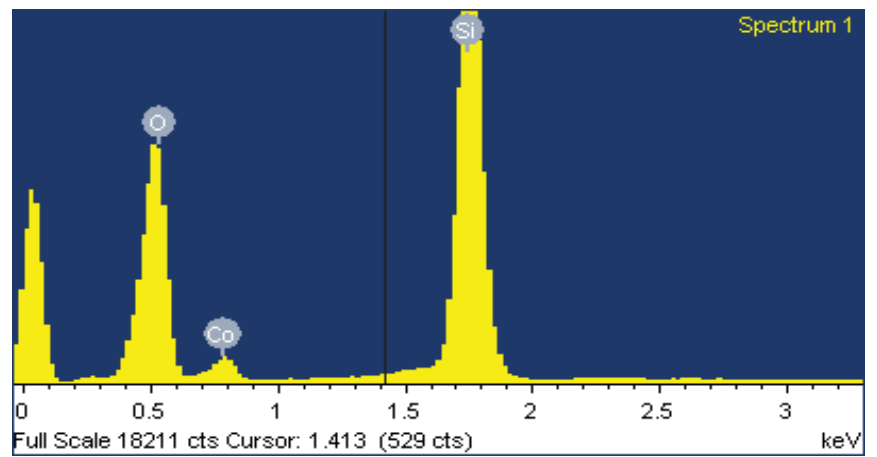

Figure 1: Spectrum of elemental composition of Calcined mesoporous $15.60 \%$ Co/SBA-15 silica.

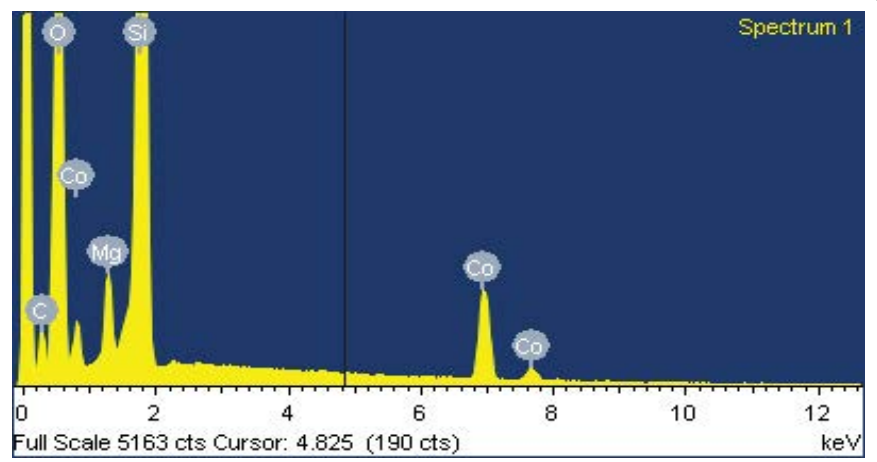

Figure 2: Spectrum of elemental composition of $6.73 \%$ Co/SBA-15 promoted with $1.38 \% \mathrm{Mg}$

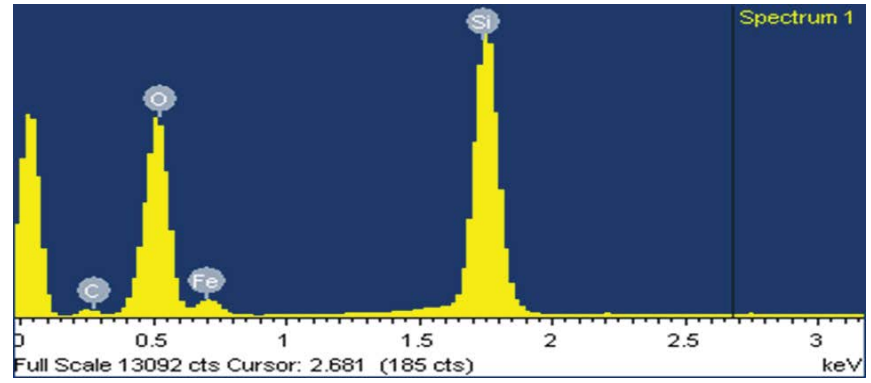

Figure 3: Spectrum of elemental composition of $29.19 \%$ Fe loading on silica SBA-15.

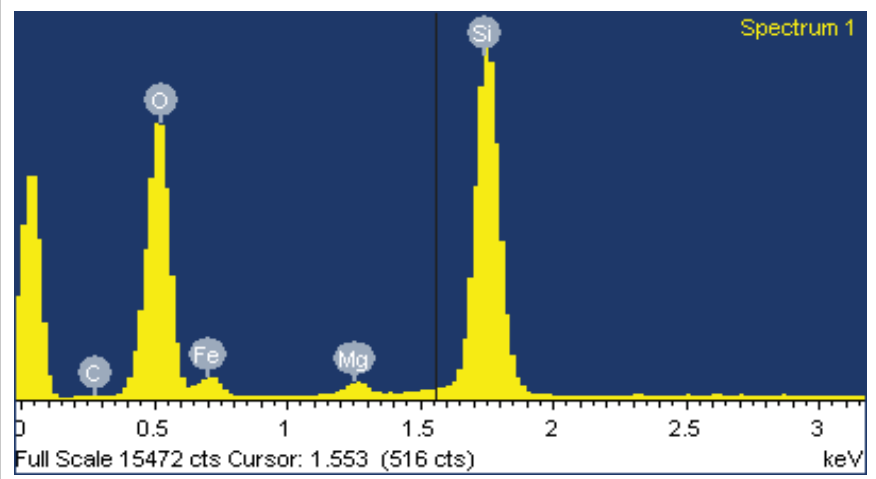

Figure 4: Spectrum of elemental composition of $28.82 \%$ Fe/SBA-15 promoted with $1.02 \% \mathrm{Mg}$

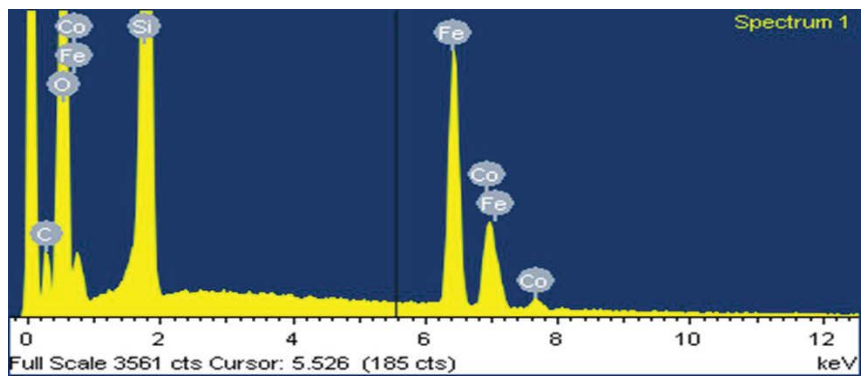

Figure 5: Spectrum of elemental composition of bimetallic loading comprising of $14.37 \% \mathrm{Fe}$ and $5.41 \%$ Co supported on SBA-15 silica.

\begin{tabular}{|c|c|c|}
\hline Element & Weight $\%$ & Atomic\% \\
\hline OK & 47.90 & 65.68 \\
\hline Si K & 36.50 & 28.51 \\
\hline Co K & 15.60 & 5.81 \\
\hline Total & 100.00 & 100.00 \\
\hline
\end{tabular}

Table 1: Results showing weight $\%$ and the atomic $\%$ of $15.60 \%$ cobalt loading on SBA-15.

\begin{tabular}{|c|c|c|}
\hline Element & Weight\% & Atomic\% \\
\hline C K & 11.30 & 17.87 \\
\hline O K & 47.70 & 56.64 \\
\hline Mg K & 1.38 & 1.08 \\
\hline Si K & 32.89 & 22.24 \\
\hline Total & 6.73 & 2.17 \\
\hline
\end{tabular}

Table 2: Results of $6.73 \%$ Co/SBA-15 loading and promoted with $1.38 \% \mathrm{Mg}$. 
Citation: Sainna MA, Abba MK (2016) Catalyst and Catalysis for Fischer-Tropsch Synthesis: A Comparative Analysis of Iron and Cobalt Catalysts on SBA-15. J Thermodyn Catal 7: 172. doi:10.4172/2160-7544.1000172

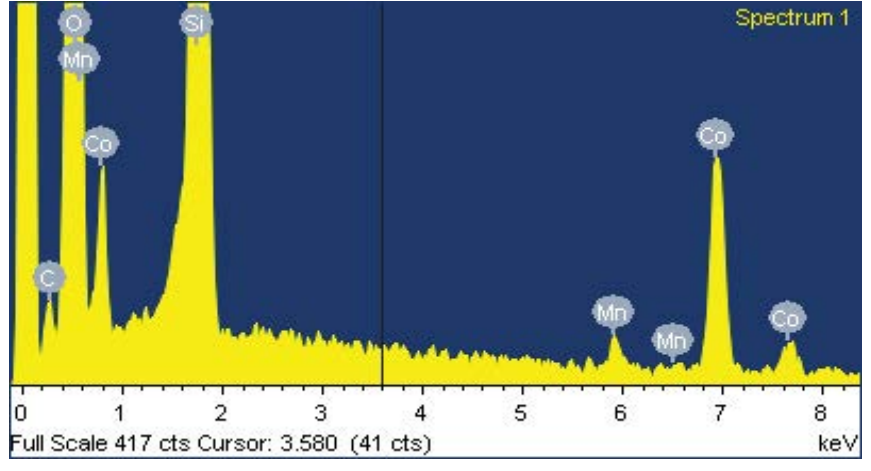

Figure 6: Spectrum illustrating the elemental composition of Co/SBA-15 promoted with $0.61 \% \mathrm{Mn}$.

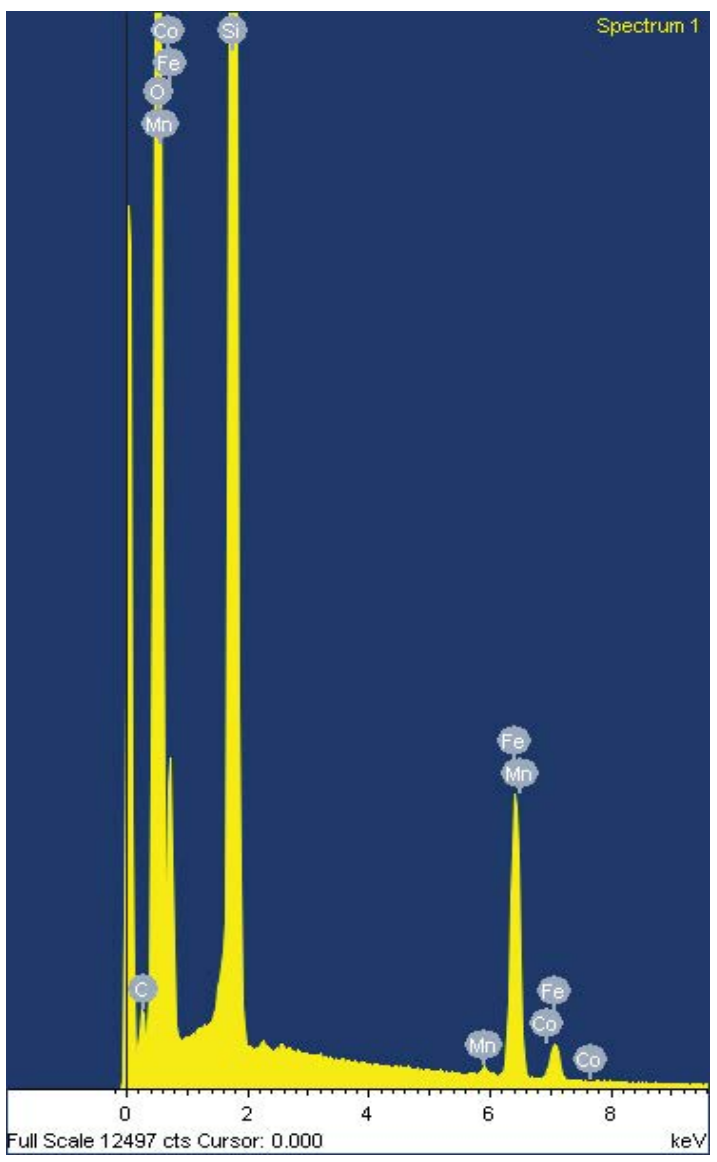

Figure 7: Elemental composition of $33.48 \%$ Fe/SBA-15 promoted with $0.50 \% \mathrm{Mn}$.

catalyst respectively after calcination; As can be observed from both images of the prepared catalyst at a magnification of $4.5 \mu \mathrm{m}$ above, it can be seen that the catalysts were agglomerated and this is simply due to the fact that both catalyst lost the components of the precursors like the nitrates, water, the Tri-block copolymer used during preparation [poly (ethylene glycol)-poly (propylene glycol)-poly (ethylene-glycol)]. The absence of these residues of these components is as a result of the calcination of the prepared catalysts at $400^{\circ} \mathrm{C}$ as explained earlier. Even though the image of $\mathrm{Fe} / \mathrm{SBA}-15$ shows some of the mesoporous structures where broken, it is obvious that the pores are not blocked by some surfactants to reduce the active metal dispersion on the support.
Therefore, calcination of the catalyst before and after impregnation will increase surface area of the catalyst.

\section{X-Ray Diffraction (XRD) spectroscopy result evaluation}

$\mathrm{X}$-ray diffraction spectroscopy pattern of an un-promoted as well as the magnesium and manganese promoted iron and cobalt catalysts prepared are calcined at $400^{\circ} \mathrm{C}$ together with those of the bulk $\mathrm{Co} \mathrm{O}_{3}$ spinel's phase are presented below. All samples were prepared using cobalt nitrate and iron (III) nitrates precursors. It is apparent from the samples diffraction peaks, all cobalt catalysts showed reflection characteristics of the $\mathrm{Co}_{3} \mathrm{O}_{4}$ spinel for the cobalt catalyst by observing an intense peak which is usually expected at $36.90^{\circ}$; the peak becomes narrower as the percentage of the cobalt increases indicating an increase of the mean $\mathrm{Co}_{3} \mathrm{O}_{4}$ particles. Although the intensity of the peaks

\begin{tabular}{|c|c|c|}
\hline Element & Weight $\%$ & Atomic\% \\
\hline C K & 6.18 & 11.88 \\
\hline O K & 36.97 & 53.33 \\
\hline Si K & 27.65 & 22.72 \\
\hline Fe K & 29.19 & 12.06 \\
\hline Totals & 100.00 & 100.00 \\
\hline
\end{tabular}

Table 3: Results of $29.19 \%$ Fe/SBA-15 loading.

\begin{tabular}{|c|c|c|}
\hline Element & Weight $\%$ & Atomic\% \\
\hline C K & 3.43 & 6.65 \\
\hline O K & 39.68 & 57.85 \\
\hline Mg K & 1.07 & 1.02 \\
\hline Si K & 27.01 & 22.43 \\
\hline Fe K & 28.82 & 12.04 \\
\hline Totals & 100.00 & 100.00 \\
\hline
\end{tabular}

Table 4: Results of $28.82 \%$ Fe/SBA-15 loading promoted with $1.07 \% \mathrm{Mg}$.

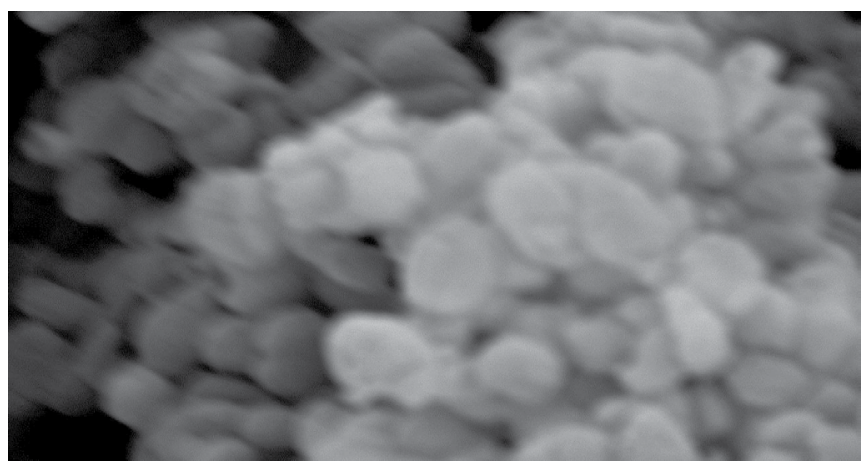

Figures 8: SEM image of mesoporous $15.60 \%$ Co/SBA-15.

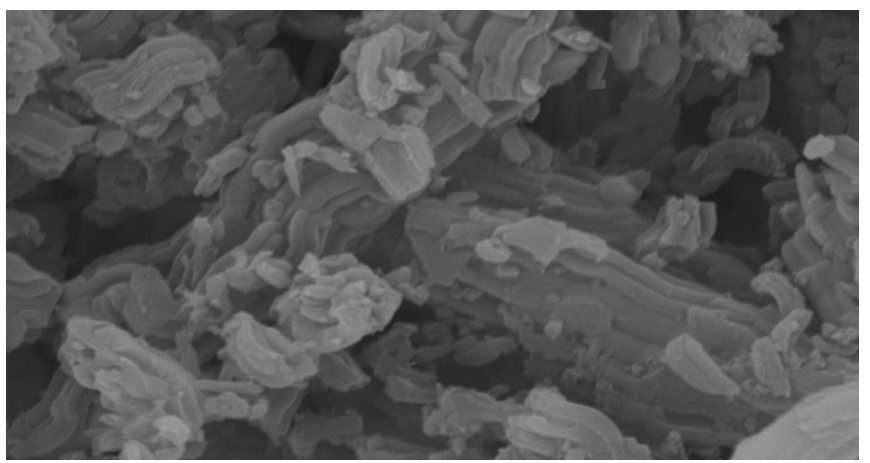

Figures 9: SEM image of mesoporous $29.19 \%$ Fe/SBA-15. 


\begin{tabular}{|c|c|c|}
\hline Element & Weight $\%$ & Atomic\% \\
\hline C K & 12.46 & 21.32 \\
\hline O K & 39.65 & 50.93 \\
\hline Si K & 28.11 & 20.57 \\
\hline Fe K & 14.37 & 5.29 \\
\hline Co K & 5.41 & 1.89 \\
\hline Totals & 100.00 & 100.00 \\
\hline
\end{tabular}

Table 5: Results of bimetallic loading of $14.37 \%$ Fe and $5.41 \%$ Co supported on SBA-15 silica.

\begin{tabular}{|c|c|c|}
\hline Element & Weight\% & Atomic\% \\
\hline C K & 8.85 & 14.34 \\
\hline O K & 48.76 & 59.3 \\
\hline Si K & 34.05 & 23.59 \\
\hline Mn K & 0.61 & 0.22 \\
\hline Co K & 7.73 & 2.55 \\
\hline Totals & 100.00 & 100.00 \\
\hline
\end{tabular}

Table 6: Results of $7.73 \%$ Co SBA-15 silica promoted with $0.61 \% \mathrm{Mn}$

\begin{tabular}{|c|c|c|}
\hline Element & Weight\% & Atomic\% \\
\hline C K & 3.62 & 7.26 \\
\hline O K & 38.06 & 57.25 \\
\hline Si K & 24.33 & 20.85 \\
\hline Fe K & 33.48 & 14.42 \\
\hline Mn K & 0.50 & 0.22 \\
\hline Totals & 100.00 & 100.00 \\
\hline
\end{tabular}

Table 7: Results of $33.48 \%$ Fe SBA-15 silica promoted with $0.50 \% \mathrm{Mn}$.

are much lower than expected for some of the cobalt loaded catalyst, which could be due to the dispersion of the metal oxides $\left(\mathrm{Co}_{3} \mathrm{O}_{4}, \mathrm{CoO}\right.$ and $\mathrm{Fe}_{\mathrm{O}}$ ) on the surface of the SBA-15 silica rather than within the SBA- 15 silica as desired. On the other hand, by promoting the Co/SBA15 silica with Magnesium, it significantly increases the dispersion of the cobalt and the iron. Although, the increase in dispersion and the presence of $\mathrm{Mn}$ favors a strong interaction of the cobalt oxides with the support and possibly $\mathrm{MnO}$ phase can lead to a drastic catalyst deactivity of up to $50 \%$ as compared with the unpromoted one [53]. In the case of the iron catalyst, the wide angle shows a very sharp and unexpectedly long peak which is also an indication that some of the irons were dispersed on the surface of the SBA-15 silica support (Figure 10).

The wide angle diffractogram above indicate the cobalt peak within the different mesoporous silica SBA-15 prepared and impregnated with different percentage of cobalt nitrate, the peaks of $\mathrm{Co}_{3} \mathrm{O}_{4}$ crystals were obvious in each of the catalyst diffractogram which is at an angle of $36.5^{\circ}$ as expected [52]. The peak for the catalyst with $15.60 \%$ Cobalt loading is higher among the rest with a lower cobalt loading; it is arranged according to (Series 4) $15.60 \%$ Co, (Series 3) $6.73 \%$ Co, (Series 2) $7.73 \% \mathrm{Co}$, (Series 1) $5.41 \mathrm{Co}$ in a bimetallic catalyst. The catalyst with lower loading has less intense peak as compared to the catalyst with higher loading. According to Martinez et al. [52], the characteristics peak of $\mathrm{Co}_{3} \mathrm{O}_{4}$ by the diffractogram is not very obvious at $36.5^{\circ}$ at a lower Coloading. The mesoporous structures seems to be dependent on the quantity of the metal loading on the support has been observed after calculating the crystallite sizes of each of the samples prepared using shearers equation. The table below shows the average crystallite diameters of each of the sample prepared (Table 8).

The table above indicates the metal loading expected theoretically, what was obtained after preparation and the crystallite size diameter of each of the samples prepared after calculating using the shearer's equation. The percentage of the reduced catalyst and the percentage of metal dispersion on the mesoporous SBA-15 silica support are also calculated using the interatomic distance equations [38-40]. As can be observed from the Table, the samples with higher metal loading has the larger particle size, this confirms the dependent of the metal loading on the particle size (Figure 11).

The above diffractogram compares the different iron catalyst supported with SBA-15 silica with the iron loaded at different proportion. The $\mathrm{Fe}_{2} \mathrm{O}_{3}$ peak is expected at an angle of $24.3^{\circ}, 33.4^{\circ}$, and $35.6^{\circ}$ as reported [53]. The diffractogram is arranged according to (Series 4) $29.19 \% \mathrm{Fe}$, (Series 3) $28.82 \% \mathrm{Fe}$, (Series 2) $33.48 \% \mathrm{Fe}$, and (Series 1) $14.37 \% \mathrm{Fe}$ for the bimetallic loading. It is important to understand the fact that larger metal oxide crystallite diameter as compared to the pore diameter of the SBA-15 silica support will lead to the dispersion of the crystal on the surface of the SBA-15 silica and not within the meso-channels of the support. This can be identified by observing the XRD of the catalyst by having rough surface with unclear peaks as can be observed from the XRD patterns of "Series 4" above. For a very well dispersion of the metal on the support, three well resolved diffraction peaks of $\mathrm{d}_{100}, \mathrm{~d}_{110}$, and $\mathrm{d}_{200}$ associated with p6mm hexagonal symmetry can be obtained showing that the mesostructure was highly ordered. The crystallite size of the SBA-15 silica support is usually around 6-15 nm [31], however the diffractogram clearly showed the dispersion of the metals on the surface of the support which means that the average diameter of the crystal is larger than that of the support which leads to the dispersion of the metal on the surface. A very narrow and highly intense peak was also observed on the $29.19 \% \mathrm{Fe} / \mathrm{SBA}-15$ silica which is also due to the dispersion of the metal on the surface of the support [54] (Figure 12).

\section{Temperature programmed reduction evaluation}

Figure 13 below shows the Temperature programmed reduction (TPR) peaks of cobalt oxides in an atmosphere of hydrogen which is recorded using the CATLAB-PCS (Micro-reactor with integrated mass spectrometer) [34] at $500^{\circ} \mathrm{C}$ (at an ascending heating rate of $15^{\circ} \mathrm{C}$ per minute). The first series (Series 2 ) on the graph for Hydrogen shows two peaks where the reduction of the cobalt oxide crystals occurred from $\mathrm{Co}_{2} \mathrm{O}_{3}$ to $\mathrm{CoO}$ and the second peak is a reduction of $\mathrm{CoO}$ to Co-zero which is in the reduced state. This peaks were proven by the

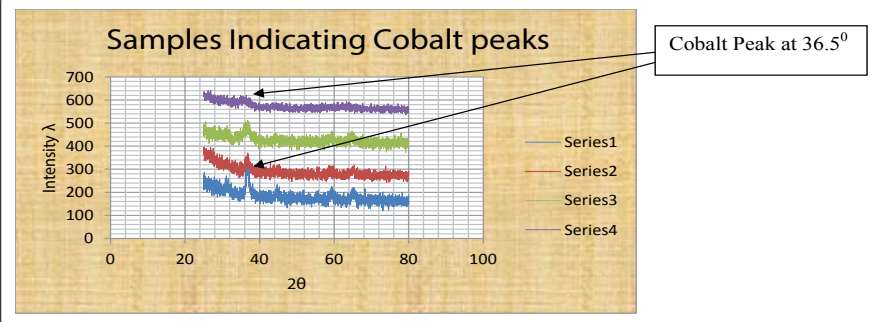

Figure 10: Wide angle diffractogram indicating cobalt peaks of various samples at an angle of $36.5^{\circ}$ as expected.

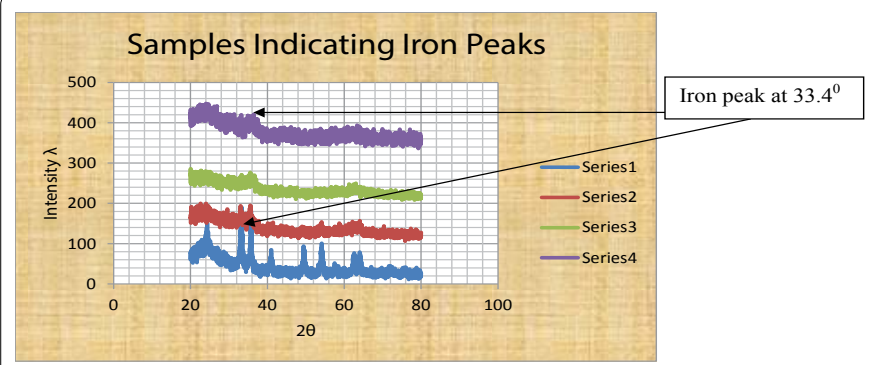

Figure 11: Wide angle diffractogram indicating Iron peaks of various samples at an angle of $33.4^{\circ}$ as expected. 


\begin{tabular}{|c|c|c|c|c|c|}
\hline Catalyst & $\begin{array}{l}\text { (wt\%) of metal loading } \\
\text { expected Theoretically }\end{array}$ & $\begin{array}{l}\text { (wt\%) of metal loaded } \\
\text { practically }\end{array}$ & $\begin{array}{l}\text { Average Crystal } \\
\text { diameter }(\mathbf{n m})\end{array}$ & $\begin{array}{l}\text { (Wt\%) Reduced metal } \\
\text { catalyst }\end{array}$ & $\begin{array}{l}\text { (Wt\%) Metal } \\
\text { dispersion }\end{array}$ \\
\hline Co/SBA-15 silica & 35 & 15.60 & 13.2 & 9.9 & 9.6 \\
\hline $\begin{array}{c}\text { Co/SBA-15 } \\
\text { Silica promoted with } \mathrm{Mg}\end{array}$ & 34 & 6.73 & 8.7 & 6.5 & 14.8 \\
\hline $\begin{array}{l}\text { Co/SBA-15silica } \\
\text { promoted with } \mathrm{Mn}\end{array}$ & 30 & 7.73 & 10.5 & 7.9 & 12.2 \\
\hline Fe/SBA-15 silica & 35 & 29.19 & 15.3 & 11.5 & 8.3 \\
\hline $\begin{array}{l}\text { Fe/SBA-15silica } \\
\text { Promoted with Mg }\end{array}$ & 35 & 28.82 & 8.3 & 6.3 & 15.2 \\
\hline $\begin{array}{l}\text { Fe/SBA-15 silica } \\
\text { promoted with } \mathrm{Mn}\end{array}$ & 35 & 33.48 & 13.2 & 9.9 & 9.6 \\
\hline Fe-Co/SBA-15 silica & Fe 20 , Co 10 & Fe 14.37, Co 5.41 & 8.1 & 6.1 & 15.7 \\
\hline
\end{tabular}

Table 8: Table indicating the percentage of metal loading expected theoretically and the percentage obtained practically together with the average particle sizes for each of the catalyst, the percentage of reduced metal catalyst and the percentage metal dispersion.

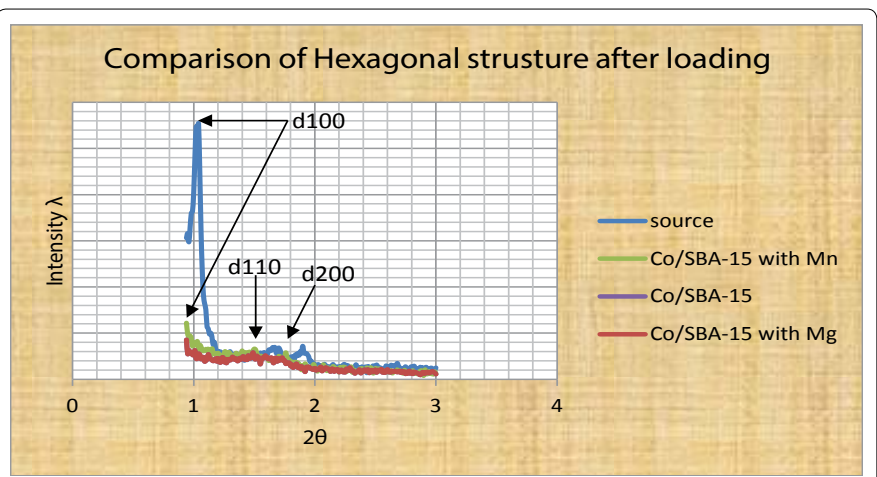

Figure 12: Comparison of Hexagonal structures after loading of Co/SBA-15 at different quantity.

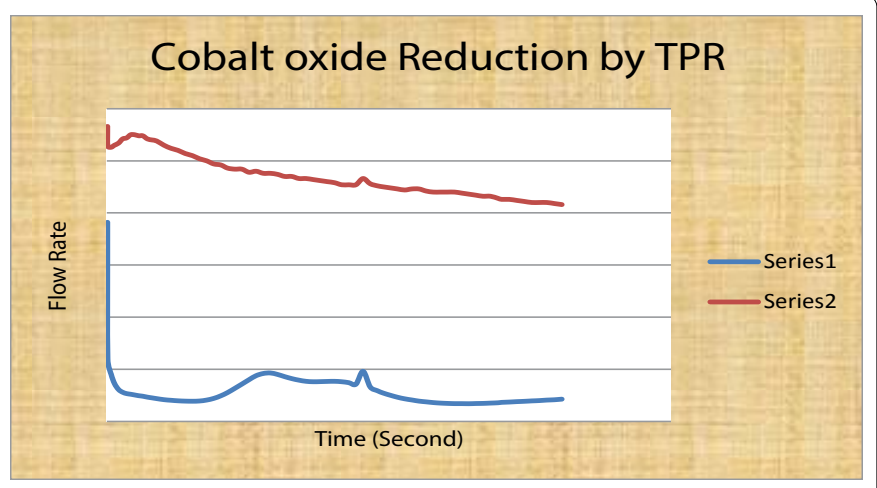

Figure 13: Graph of Cobalt oxide reduction by Temperature Programmed Reduction technique using CATLAB-PCS Microreactor. The Graph is showing the peaks at a reduction of $\mathrm{Co}_{2} \mathrm{O}_{3}$ to $\mathrm{CoO}$ (Series 1), and a reduction of $\mathrm{CoO}$ to Co-zero.

peaks (Series 1) observed by formation of water at an align position to the peaks formed by hydrogen, the first reduction occurred at a temperature less than $350^{\circ} \mathrm{C}$ and the second reduction occurred at a temperature less than $450^{\circ} \mathrm{C}$ as can be observed from the graph above. The temperature programmed reduction techniques sometimes gives quantitative and qualitative picture of the catalyst surface reducibility as well as its sensitivity to promoters chemical changes or metal/ support interactions (Figure 13).

\section{Conclusions}

The seven different samples of Fischer Tropsch catalyst where prepared and the physico-chemical properties of their mesoporous
SBA-15 supported format was investigated as a function of the metal loading, percentage dispersion of the metal on the support, effect of magnesium $(\mathrm{Mg})$ and manganese $(\mathrm{Mn})$ promoters, the average crystal diameter in each of the sample. Calcined samples of Co/SBA-15 prepared from Co (II) nitrate hexahydrate with cobalt loading of 15.60 wt $\%$ practically, another $6.73 \mathrm{wt} \% \mathrm{Co} / \mathrm{SBA}-15$ promoted with $\mathrm{Mg}$, $7.73 \mathrm{wt} \% \mathrm{Co} / \mathrm{SBA}-15$ promoted with $\mathrm{Mn}$ where all characterized using $\mathrm{XRD}, \mathrm{EDX} / \mathrm{SEM}$ and TPR and it was concluded as follows;

- The average crystal diameter is observed to be larger in iron catalyst and this could be due to the fact that Fe metal has higher percentage loading on the support than the cobalt; this indicates the dependence of metal loading on the average crystal diameter. i.e., the higher the metal loading on the support, the larger the average crystal diameter.

- According to the observation on the wide angle pattern, it can be considered that the strong interaction of the support and the metal catalyst loaded can lead to high dispersion of the metal catalyst loaded within the meso-channels of the support, and this will lead to a weak peak on the wide angle diffractogram of the samples.

- The dispersion of the active metal sizes of Cobalt and iron samples increases with the addition of promoter, however it increases most with the magnesium promoter $(\mathrm{Mg})$ which has the highest dispersion of $14.8 \mathrm{wt} \%$ on $6.73 \% \mathrm{Co} / \mathrm{SBA}-15$, and $15.2 \mathrm{wt} \%$ on $28.82 \% \mathrm{Fe} / \mathrm{SBA}-15$ as compared to manganese promoter with 12.2 wt $\%$ dispersion on $7.73 \% \mathrm{Co} / \mathrm{SBA}-15$ and $9.6 \mathrm{wt} \%$ dispersion on $33.43 \%$ Fe/SBA-15. However, an increase in Mn promoter favors a strong interaction of the metal oxide with the support and perhaps with the $\mathrm{MnO}$ component generating a catalyst that maybe about $50 \%$ less active than the un- promoted catalyst sample [52].

- The dispersion was also observed to be high with the bimetallic $14.37 \%$ Fe-5.41\% Co/SBA- 15 catalyst with the active metal dispersion on the support of $15.7 \%$ was observed.

- It should be well-known that the absence of intense reflection at expected peaks by the wide angle XRD in an active metal catalyst suggest the formation of either small metal crystal particles that is undetectable by the X-ray diffractogram, or it means the disintegration of the mesoporous structure. Likewise for the small angle, the absence of the peaks at $\mathrm{d}_{100}, \mathrm{~d}_{110}$ and $\mathrm{d}_{200}$ might be due to the collapse of the hexagonal structure of the support as observed from the XRD pattern of the small angles XRD result [52-56].

\section{Acknowledgements}

MAS and AMK thanks the Petroleum Technology Development Fund for a studentship. 


\section{References}

1. Zhao Y, Klie RF (2011) J Underg Research 25: 25-28.

2. Wilson TP, Paul HK, Ellgen PC (1981) J Cata 69: 193-201.

3. Knop-Gericke A, Havecker M, Schedel-Niedrig T, Schlogl R (2000) Top Catal 10: 187.

4. Kobayashi M, Kobayashi $H$ (1972) Application of transient response method to the study of heterogeneous catalysis: I. Nature of catalytically active oxygen on manganese dioxide for the oxidation of carbon monoxide at low temperatures. J Cataly 27: 100-107.

5. Kobayashi M, Kobayashi H (1972) Application of transient response method to the study of heterogeneous catalysis: II. Mechanism of catalytic oxidation of carbon monoxide on manganese dioxide. J Catal 27: 108-113.

6. Kobayashi M, Kobayashi H (1972) Application of transient response method to the study of heterogeneous catalysis: III. Simulation of carbon monoxide oxidation under an unsteady state. J Catal 27: 114-119.

7. Dekker FHM, Nazloomian J, Bliek GA, Kapteijn F, Moulijn JA, et al. (1997) J Appl Catal A 151: 247-266.

8. Olea M, Kunitake M, Shido T, Iwasawa Y (2001) TAP study on CO oxidation on a highly active $\mathrm{Au} / \mathrm{Ti}(\mathrm{OH})_{4}{ }^{*}$ catalyst. Phys Chem Chem Phys 3: 627-631.

9. Buyevskaya OV, Wolf, D, Baerns M (1994) Rhodium-catalyzed partial oxidation of methane to $\mathrm{CO}$ and $\mathrm{H}_{2}$. Transient studies on its mechanism. Catal Lett 29 : $249-260$

10. Schuurman Y, Mirodatos C (1997) Uses of transient kinetics for methane activation studies. Appl Catal A 151: 305-331.

11. Aparicio LM (1997) Transient isotopic studies and microkinetic modeling of methane reforming over nickel catalysts. J Catal 165: 262-274.

12. Heitnes Hofstad K, Hoebink JHBJ, Holmen A, Marin GB (1998) Partial oxidation of methane to synthesis gas over rhodium catalysts. Catal Today 40: 157-170.

13. Berger-Karin C, Sebek M, Pohl MM, Bentrup U, Kondra-tenko VA, et al. (2012) Chem Cat Chem 4: 1368-1375.

14. Keiski RL, Salmi T, Niemisto $P$, Ainassaari J, Pohjola V (1996) Stationary and transient kinetics of the high temperature water-gas shift reaction. J Appl Catal A 137: 349-370.

15. Kalamaras CM, Panagiotopoulou P, Kondarides DI, Efstathiou AM (2009) Kinetic and mechanistic studies of the water-gas shift reaction on $\mathrm{Pt} / \mathrm{TiO}$ catalyst. J Catal 264: 117-129.

16. Kala-maras CM, Petallidou KC, Efstathiou AM (2013) The effect of La 3+-doping of $\mathrm{CeO} 2$ support on the water-gas shift reaction mechanism and kinetics over $\mathrm{Pt} / \mathrm{Ce} 1-\mathrm{x}$ La $\mathrm{O}_{2}-\delta$. Appl Catal B 136: 225-238.

17. Wainwright MS, Hoffman TW (1977) The oxidation of ortho-xylene on vanadium pentoxide catalysts. I. Transient kinetic measurements. J Chem Eng 55: 552-556.

18. Hinz A, Nilsson B, Andersson A (2000) Simulation of transients in heterogeneous catalysis: a comparison of the step-and pulse-transient techniques for the study of hydrocarbon oxidation on metal oxide catalysts. Chem Eng Sci 55: 4385-4397.

19. Gleaves JT, Ebner JR, Kuechler TC (1988) Temporal analysis of products (TAP)-a unique catalyst evaluation system with submillisecond time resolution. Catal Rev 30: 49-116.

20. Gleaves JT, Yablonsky G, Zheng X, Fushimi R, Mills PL (2010) Tempora analysis of products (TAP)-recent advances in technology for kinetic analysis of multi-component catalysts. Journal of Molecular Catalysis A: Chemical 315 108-134.

21. Angeli SD, Mon teleone G, Giaconia A, Lemonidou AA (2014) State-of-the-art catalysts for $\mathrm{CH}_{4}$ steam reforming at low temperature. Int J Hydrogen Energy 39: 1979 -1997.

22. Duarte RB, Nachtegaal M, Bueno JMC, van BoKhoven JA (2012) Understanding the effect of $\mathrm{Sm}_{2} \mathrm{O}_{3}$ and $\mathrm{CeO}_{2}$ promoters on the structure and activity of $\mathrm{Rh} /$ Al2O3 catalysts in methane steam reforming. J Catal 296: 86-98.

23. Wei JM, Iglesia E (2004) Mechanism and Site Requirements for Activation and Chemical Conversion of Methane on Supported Pt Clusters and Turnover Rate Comparisons among Noble Metals. J Phys Chem B 108: 4094-4103.

24. Wei JM, Iglesia E (2004) Structural requirements and reaction pathways in methane activation and chemical conversion catalyzed by rhodium. J Catal 225: 116-127.
25. Wei JM, Iglesia E (2004) Isotopic and kinetic assessment of the mechanism of reactions of $\mathrm{CH} 4$ with $\mathrm{CO}_{2}$ or $\mathrm{H}_{2} \mathrm{O}$ to form synthesis gas and carbon on nickel catalysts. J Catal 224: 370-383.

26. Craciun, R, Daniell, W, Knozinger, $\mathrm{H}$ (2002) The effect of CeO 2 structure on the activity of supported $\mathrm{Pd}$ catalysts used for methane steam reforming. App Catal A 230: 153-168.

27. Sainna MA, Singh D, Kumar D, de Visser SP (2015) A Trimetal Carbene with Reactivity Reminiscent of Fischer-Tropsch Catalysis. Organometallics 34 $1651-1660$.

28. Halabi MH, De Croon MHJM, van der Schaaf J, Cobden PD, Schouten JC, et al. (2010) Intrinsic kinetics of low temperature catalytic methane-steam reforming and water-gas shift over $\mathrm{Rh} / \mathrm{Ce} \alpha \mathrm{Zr} 1-\mathrm{aO}_{2}$ catalyst Appl Catal $\mathrm{A}$ General 389: 80-91.

29. Halabi MH, De Croon MHJM, van der Schaaf J, Cobden PD, Schouten JC, et al. (2010) Low temperature catalytic methane steam reforming over ceriazirconia supported rhodium. Applied Catalysis A: General 389: 68-79.

30. Kurungot S, Yamaguchi T (2004) Stability improvement of Rh/ $\mathrm{Y}-\mathrm{Al} 2 \mathrm{O} 3$ catalys layer by ceria doping for steam reforming in an integrated catalytic membrane reactor system. Catal Lett 92: 181-187.

31. Quan ZA, Qin YN, Liu C (1991) Promoting effect of cerium oxide in supported nickel catalyst for hydrocarbon steam-reforming. Appl Catal 70: 1-8.

32. Van Santen RA (2009) Complementary structure sensitive and insensitive catalytic relationships. Acc Chem Res 42: 57-66

33. Duarte RB, Safonova OV, Krumeich F, Makosch M, Van Bokhoven JA (2013) Oxidation State of $\mathrm{Ce}$ in $\mathrm{CeO} 2-P r o m o t e d \mathrm{Rh} / \mathrm{Al} 2 \mathrm{O} 3$ Catalysts during Methane Steam Reforming: $\mathrm{H} 2 \mathrm{O}$ Activation and Alumina Stabilization. ACS Catal 3 : 1956-1964.

34. Chin YH, Buda C, Neurock M, Iglesia E (2013) Consequences of metal-oxide interconversion for $\mathrm{C}-\mathrm{H}$ bond activation during $\mathrm{CH} 4$ reactions on $\mathrm{Pd}$ catalysts. J Am Chem Soc 135: 15425-15442.

35. Buyevskaya OV, Walter K, Wolf D, Baerns M (1996) Primary reaction steps and active surface sites in the rhodium-catalyzed partial oxidation of methane to $\mathrm{CO}$ and $\mathrm{H}_{2}$. Catal Lett 38: 81-88.

36. Wang DZ, Dewaele O, DeGroote AM, Froment GF (1996) Reaction mechanism and role of the support in the partial oxidation of methane on $\mathrm{Rh} / \mathrm{Al}_{2} \mathrm{O}_{3}$. J Cata 159: $418-426$.

37. Shaikhutdinov S, Heemeier M, Baumer M, Lear T, Lennon D, et al. (2001) Structure-Reactivity Relationships on Supported Metal Model Catalysts: Adsorption and Reaction of Ethene and Hydrogen on $\mathrm{Pd} / \mathrm{Al}_{2} \mathrm{O}_{3} / \mathrm{NiAl}$ (110). J Cata I 200: 330-339.

38. Chou P, Vannice MA (1987) Calorimetric heat of adsorption measurements on palladium. I. Influence of crystallite size and support on hydrogen adsorption. J Catal 104: 1-16.

39. Bernal S, Calvino JJ, Cifredo GA, Laachir A, Perrichon V, et al. (1994) Influence of the Reduction/Evacuation Conditions on the Rate of Hydrogen Spillover on $\mathrm{Rh} / \mathrm{CeO}_{2}$ Catalysts. Langmuir 10: 717-722.

40. Bernal S, Calvino JJ, Cifredo GA, Rodriguez-Izquierdo JM, Perrichon V, et al. (1992) Reversibility of hydrogen chemisorption on a ceria-supported rhodium catalyst. J Catal 137: 1-11.

41. Gritschneder S, Reichling $\mathrm{M}$ (2007) Structural elements of $\mathrm{CeO}_{2}(111)$ surfaces. Nanotechnology 18: 1-6.

42. Yang ZX, Wang Q, Wei S, Ma D, Sun Q (2010) The Effect of Environment on the Reaction of Water on the Ceria(111) Surface: A DFT+U Study. J Phys Chem C 114: 14891-14899.

43. Molinari, M, Parker, S. C, Sayle, D. C, Islam, M. S. Water Adsorption and Its Effect on the Stability of Low Index Stoichiometric and Reduced Surfaces of Ceria. J. Phys. Chem. C 2012, 116, 7073 - 7082.

44. Norrish K, Taylor RM (1962) Quant Diffrac Ana, pp: 98-109.

45. Sainna MA, Kumar S, Kumar D, Fornarini S, Crestoni ME, et al. (2015) A comprehensive test set of epoxidation rate constants for iron(IV)-oxo porphyrin cation radical complexes. Chem Sci 6: 1516-1529.

46. Peri JB (1965) Infrared and Gravimetric Study of the Surface Hydration of Y-Alumina. J Phys Chem 69: 211-219. 
Citation: Sainna MA, Abba MK (2016) Catalyst and Catalysis for Fischer-Tropsch Synthesis: A Comparative Analysis of Iron and Cobalt Catalysts on SBA-15. J Thermodyn Catal 7: 172. doi:10.4172/2160-7544.1000172

47. Hass KC, Schneider WF, Curioni A, Andreoni W (2000) First-Principles Molecular Dynamics Simulations of $\mathrm{H}_{2} \mathrm{O}$ on $\mathrm{a}-\mathrm{Al}_{2} \mathrm{O}_{3}(0001) \mathrm{J}$ Phys Chem B 104: 5527-5540.

48. Fathi M, Monnet F, Schuurman Y, Holmen A, Mirodatos C (2000) Reactive oxygen species on platinum gauzes during partial oxidation of methane into synthesis gas. J Catal 190: 439-445.

49. Wang R, Xu HY, Liu XB, Ge QJ, Li WZ (2006) Role of redox couples of Rh 0/ $\mathrm{Rh} \delta+$ and $\mathrm{Ce} 4+/ \mathrm{Ce} 3+$ in $\mathrm{CH}_{4} / \mathrm{CO}_{2}$ reforming over $\mathrm{Rh}-\mathrm{CeO}_{2} / \mathrm{Al}_{2} \mathrm{O}_{3}$ catalyst. Appl Catal A 305: 204-210.

50. Meng M, Zha Y, Luo J, Hu T, Xie Y, et al. (2006) A study on the catalytic synergy effect between noble metals and cobalt phases in Ce-Al-O supported catalysts. J Appl Catal A 301: 145-151.
51. Vazquez A, Lopez T, Gomez R, Bokhimi X (2001) Synthesis, characterization and catalytic properties of $\mathrm{Pt} / \mathrm{CeO}_{2}-\mathrm{Al}_{2} \mathrm{O}_{3}$ and $\mathrm{Pt} / \mathrm{La}_{2} \mathrm{O}_{3}-\mathrm{Al}_{2} \mathrm{O}_{3}$ sol-gel derived catalysts. J Mol Catal A 167: 91-99.

52. Okayama S, Haraichi S, Matsuhata H (2005) Reference sample for the evaluation of SEM image resolution at a high magnification--nanometer-scale Au particles on an HOPG substrate. J Electron Microsc (Tokyo) 54: 345-350.

53. Martínez ACL (2003) J Catal, pp: 486-499.

54. Kumar N, Singh P, Kumar S (2006) Physical, X-ray diffraction and scanning electron microscopic studies of uroliths. Indian J Biochem Biophys 43: 226-232.

55. Pattanayak BC (2010) Synthesis and Characterization of Alumina/Iron Oxide Mixed Nanocomposite. Rourkela: National Institute of Technology, Rourkela.

56. Yinyong S, Gen SWP (2006) Appl Catal A, pp: 1-7. 